\title{
A new species of phlebotomine, Trichophoromyia adelsonsouzai (Diptera: Psychodidae) of Brazilian Amazonia
}

\author{
Thiago Vasconcelos dos Santos ${ }^{1 /+}$, Fábio Márcio Medeiros da Silva ${ }^{1}$, Iorlando da Rocha Barata \\ Andrey José de Andrade², Eunice Aparecida Bianchi Galati²
}

'Laboratório de Leishmanioses, Instituto Evandro Chagas, Secretaria de Vigilância em Saúde, Ministério da Saúde, Ananindeua, PA, Brasil ${ }^{2}$ Departamento de Epidemiologia, Faculdade de Saúde Pública, Universidade de São Paulo, São Paulo, SP, Brasil

The phlebotomine sandfly Trichophoromyia adelsonsouzai sp. nov. is described and illustrated based on the male and female morphological characteristics of specimens collected at Km 27 of the Trans-Amazonian Highway, municipality of Vitória do Xingu, state of Pará, Brazilian Amazonia. This is an area subject to the direct influence of Belo Monte hydroelectric system. With the description of this new species the number of Trichophoromyia sandflies recorded in Brazil is increased to 20.

Key words: Phlebotominae - sandflies - Trichophoromyia adelsonsouzai new species - Belo Monte hydroelectric system - Amazonia

During studies of phlebotomine sandfly fauna to monitor the transmission of cutaneous leishmaniasis in the area of the direct influence of the Belo Monte hydroelectric system, state of Pará (PA), Brazil, males and females of a new species of Trichophoromyia Barretto (1962) were captured. Sampling was undertaken during 4-15 February and 10-26 July 2012 in the municipality of Vitória do Xingu at Km 27 of the Trans-Amazonian Highway between the municipalities of Altamira and Anapu in the following three localities: Acampamento Norte Energia (03²2'24.1'S 51 $\left.{ }^{\circ} 55^{\prime} 54.7^{\prime}{ }^{\circ} \mathrm{W}\right)$, Sítio Canais e Diques $\left(03^{\circ} 17^{\prime} 20.6^{\prime}\right.$ 'S 51'53'37.2'W) and Sítio Pimental $\left(03^{\circ} 20^{\prime} 50.22^{\prime \prime} \mathrm{S} 51^{\circ} 55^{\prime} 11.91^{\prime \prime} \mathrm{W}\right)$, all of them situated in a rain forest area of the Amazonian biome.

Trichophoromyia [abbreviated as Th., according to Marcondes (2007)] was established as a subgenus of Lutzomyia França, 1924 by Barretto (1962). It was later raised to genus level (Artemiev 1991, Galati 1995) and, according to this latter author, together with six other genera, constitutes the subtribe Psychodopygina (Galati 1995). Trichophoromyia comprises 37 species, most of which have a restricted geographical range within the Amazon Basin (Young \& Duncan 1994) and at least 10 species have been catalogued in PA (Aguiar \& Medeiros 2003, Galati 2003).

Both sexes of Trichophoromyia are characterised by the absence of ventrocervical sensillae, presence of Newstead's spines on the second palpomere. Males present the fifth palpomere slightly longer to the third, genitalia longer than or equal to the thorax, gonostyli

doi: 10.1590/0074-0276130159

Financial support: Norte Energia SA, FAPESP (2010/15802-7) (to AJA)

+ Corresponding author: thiagovasconcelos@iec.pa.gov.br

Received 20 March 2013

Accepted 10 July 2013 with four spines, the apical one generally being shorter than the article. Females present fifth palpomere shorter than third, lacinia of the maxilla with the external teeth distributed in two longitudinal rows, spermathecae with 25 or more rings, the apical one being generally three or more times longer than the pre-apical (Galati 2003). Most species have similar females, as regards the characteristics of the spermathecae, head and thorax; thus were it not for the males it would be impossible to distinguish between them (Barreto et al. 2002).

Little is known about the biology of Trichophoromyia. The females of most species do not seem to be highly anthropophilic. The only species of Trichophoromyia so far to be incriminated in the transmission of leishmaniasis agents is Trichophoromyia ubiquitalis (Mangabeira, 1942) (Lainson \& Shaw 1998). Although this species seems normally to be little inclined to bite human beings in the field, its participation in the transmission of Leishmania (Viannia) lainsoni Silveira, Shaw, Braga \& Ishikawa, 1987 in Amazonia is supported by the finding of females naturally infected with this parasite and is known to attack man avidly under exceptional conditions (Lainson et al. 1992). In Bolivia, Trichophoromyia velascoi (Le Pont \& Desjeux, 1992) was found naturally infected by Leishmania sp. in an area with a human case due to L. lainsoni (Martinez et al. 2001) and, recently, using real-time polymerase chain reaction, Valdivia et al. (2012) found Trichophoromyia auraensis (Mangabeira, 1942) infected with $L$. (V.) lainsoni and Leishmania (Viannia) braziliensis Vianna, 1911 in Peru.

This present paper describes a new sandfly species belonging to the Trichophoromyia genus found in PA, Brazilian Amazonia.

\section{MATERIALS AND METHODS}

Sandfly collections were performed using CDC light traps installed $1.5 \mathrm{~m}$ above the ground. The specimens were clarified according to Forattini (1973) and Ryan (1986) and mounted in Canada balsam or Berlese medium. Their measurements, obtained on a scale adapted 
to a Zeiss ${ }^{\mathrm{TM}}$ (Orlando, Florida, USA) calibrated eyepiece, are given in micrometers $(\mu \mathrm{m})$ and presented for the holotype, followed in parentheses by the measurement range of the male paratypes and the number of specimens observed; for female paratypes the measurement range is given, followed by the number in parentheses of specimens presenting the particular characteristic. The photographs were taken in a Leica ${ }^{\mathrm{TM}}$ DM5000 microscope. The terminology of the characters and the nomenclature for the sandflies are in accordance with Galati $(1995,2003)$.

Morphological and morphometrical data have been compared with type material (holotype and 1 paratype) of the closely morphogeographical species Trichophoromyia readyi (Ryan, 1986). All collections were licensed by the Brazilian Institute of Environment and Renewable Natural Resources and Chico Mendes Institute for Biodiversity Conservation (license 33710-4).

\section{RESULTS}

Trichophoromyia adelsonsouzai Santos, Silva, Barata, Andrade \& Galati, sp. nov. 2013

(Figs 1-6)

Description - Male - Head: (Fig. 1A) 360 (320-390; $\mathrm{n}=30)$ long, $350(300-370 ; \mathrm{n}=24)$ wide, ratio between length/width 1.0:1.0 (1.0-1.2:1.0; $\mathrm{n}=24)$. Clypeus 110 $(80-110 ; \mathrm{n}=31)$ long, clypeus length/head length ratio
0.3:1.0 (0.2-0.3:1.0; $\mathrm{n}=30)$; eyes $220(180-250 ; \mathrm{n}=31)$ long, $100(90-140 ; n=25)$ wide; eye length/head length ratio 0.6:1.0 (0.6-0.7:1.0; $\mathrm{n}=30)$, interocular distance 110 $(90-130 ; \mathrm{n}=27)$. Labrum-epipharynx (LE) 210 (190$260 ; \mathrm{n}=31) ; \mathrm{LE} /$ head length ratio 0.6:1.0 $(0.5-07: 1.0 ; \mathrm{n}=$ 30). Antennomere lengths: AIII: 240 (210-250; $n=31)$, AIV: 130 (117-138), AV: 133 (109-140; $\mathrm{n}=29)$, AXV: 57 $(52-75 ; \mathrm{n}=25)$ and AXVI: $65(49-75 ; \mathrm{n}=22)$. Antennomere III (Fig. 2A) with the external ascoid implanted slightly more basal than the internal one; ascoids without posterior spur, anterior prolongation long reaching the distal end of the flagellomere; AIII and AIV with the papilla implanted in the pre-apical region and it is absent on AV (Fig. 2A-C); presence of simple setae on AVIIIAXVI and AXI, AXIII, AXV, AXVI with spiniform papilla (Fig. 2D-H); AIII/LE ratio 1.14:1.0 (1.04:1:0, $\mathrm{n}=31)$. Palpomere lengths: I: 26 (26-49; $\mathrm{n}=31)$, II: 91 (78-112; $\mathrm{n}=31)$, III: $138(109-143 ; \mathrm{n}=28)$, IV: $55(52-70 ; \mathrm{n}=27)$, V: 172 (133-179; $\mathrm{n}=22$ ). Palpal formula: 1- 4- 2- 3- 5 (n = 22); palpomere II (Fig. 2I) with one Newstead's spine on the apical half and palpomere III (Fig. 2J) with 12 Newstead's spines distributed on the structure. Labial suture forming a fork.

Thorax: $570(530-620 ; \mathrm{n}=31)$ long, mesonotum 500 (450-560; $\mathrm{n}=31)$ long. Ventrocervical sensillae absent. 1-6 proepimeral setae; $6-16$ upper anepisternal setae $(\mathrm{n}=$ 30). Setae absent on the anterior katepisternum margin.

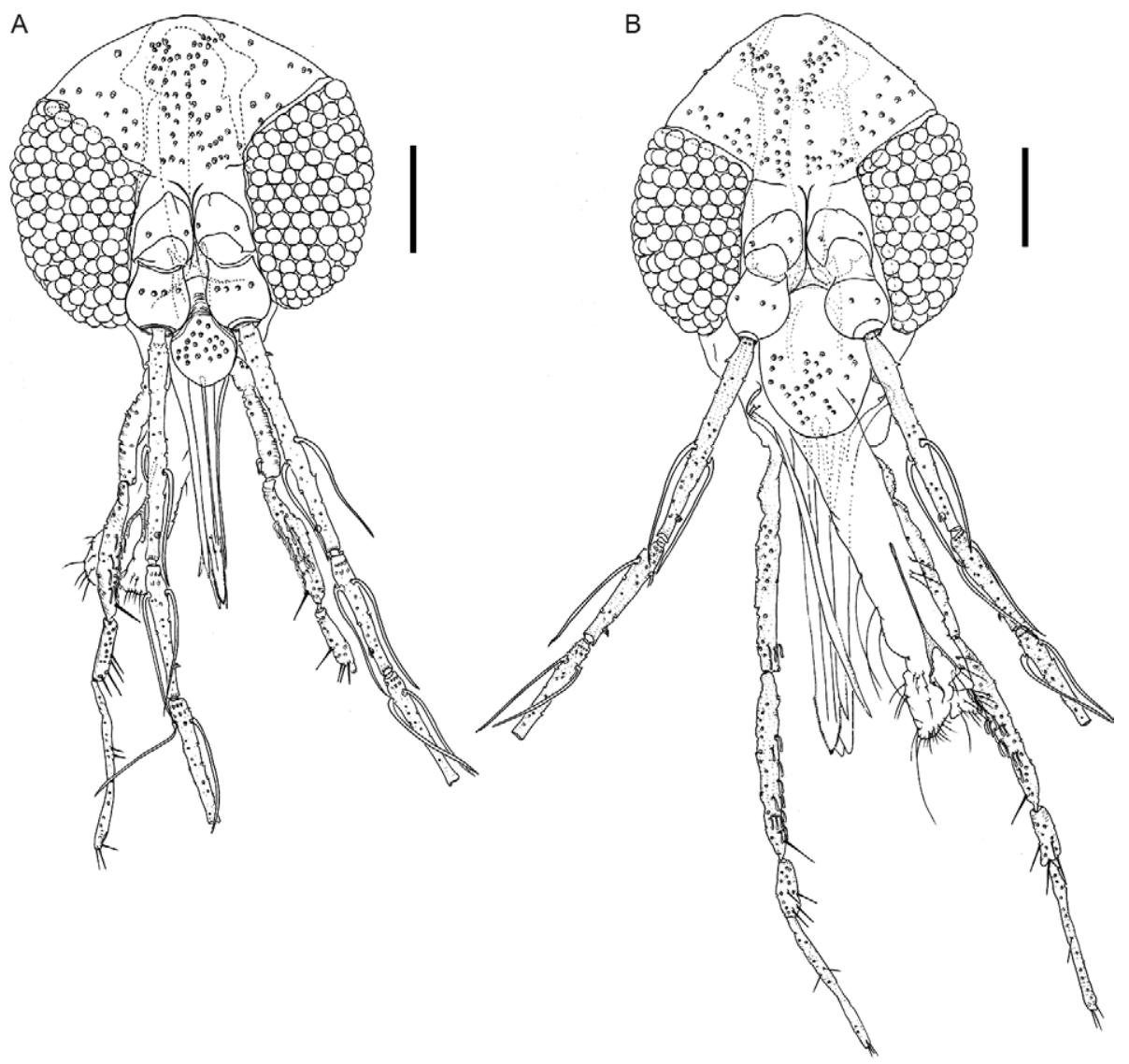

Fig. 1: Trichophoromyia adelsonsouzai sp. nov. A: male holotype head; B: female paratype head. Bar $=100 \mu \mathrm{m}$. 
Wing (Fig. 3A): 2,000 (1,850-2,200; $\mathrm{n}=24)$ long, 570 $(510-590 ; \mathrm{n}=25)$ wide; length/width ratio 3.5:1.0 (3.5-3 $.9: 1.0, \mathrm{n}=24)$; veins $\mathrm{R}_{5} 1,250(1,110-1,350 ; \mathrm{n}=23)$; alar indices: alpha 560 (490-520; $\mathrm{n}=26)$; beta $260(210-300$; $\mathrm{n}=26)$; gamma $240(160-290 ; \mathrm{n}=25)$; delta 390 (290$430 ; \mathrm{n}=26) ;$ pi $140(100-180 ; \mathrm{n}=22)$. Length of coxa, femur, tibia and tarsus I+II+III+IV+V, respectively: foreleg $330(290-350 ; \mathrm{n}=31), 810(710-870 ; \mathrm{n}=10), 1,070(990-$ $1,150 ; \mathrm{n}=9), 1,300(1,190-1,410 ; \mathrm{n}=9)$; midleg $330(300$ $360 ; \mathrm{n}=31), 780(700-850 ; \mathrm{n}=11), 1,300(1,240-1,380$; $\mathrm{n}=8), 1,570(1,430-1,600 ; \mathrm{n}=8)$; hindleg $350(300-380$; $\mathrm{n}=31), 890(830-910 ; \mathrm{n}=6), 1,500(1,510-1,800 ; \mathrm{n}=6)$, $1,700(1,620-1,790 ; n=5)$. Femora without spines.

Abdomen: 1,650 $(1,270-1,900 ; \mathrm{n}=31)$ long. Tergal papillae absent on all tergites. Terminalia (Fig. 3B): gonocoxite 390 (338-437; $\mathrm{n}=31)$ long; $161(125-172 ; \mathrm{n}=31)$ wide; sclerotised longitudinal band on its basal internal face absent. Presence of a tuft with $25(22-29 ; n=31)$ long bristles implanted in the middle of the structure (Fig. 3B, C); plus 1-2 (1-3; $\mathrm{n}=31)$ isolated basal short setae as showed in the more basal region of the gonocoxite (Figs 3B, C, 4B). Gonostylus (Fig. 3B) 260 (234-268; n $=31$ ) long, with four spines and the pre-apical spiniform setae absent; the spines having the following disposition: one apical; the superior external implanted in the $1 / 6$ apical; the inferior external in the $1 / 3$ apical and internal spines in the basal third. Paramere (Figs 3B, 4A-F): length of dorsal margin $187(156-316 ; \mathrm{n}=31)$ and ventral $260(250-468 ; \mathrm{n}=31)$; dorsal lobe $52(39-57 ; \mathrm{n}=31)$ long and $57(47-55 ; \mathrm{n}=31)$ wide. Paramere beyond hump relatively broad, presenting a dorsal curvature in apical region and in same specimens was noted that the dorsal lobe in basal region was bent downwards due to the pressure of the coverslip (Fig. 4E, F). Conic aedeagus, length of the dorsal margin $83(65-91 ; \mathrm{n}=26)$ and the ventral margin 60 (39-78; $\mathrm{n}=26)$. Lateral lobe (surstyli): 471
(429-567; $\mathrm{n}=31)$ long, $52(29-39 ; \mathrm{n}=31)$ wide and with a pointed apex without pre-apical constriction. Genital pump $192(164-205 ; \mathrm{n}=31)$ long; piston $169(143-172 ; \mathrm{n}$ =31) long; genital filaments $988(972-1,157 ; \mathrm{n}=31)$ long (Fig. 3D), 6X $(6-8 ; n=31)$ the length of the pump, tips presenting clavate form (Fig. 3D).
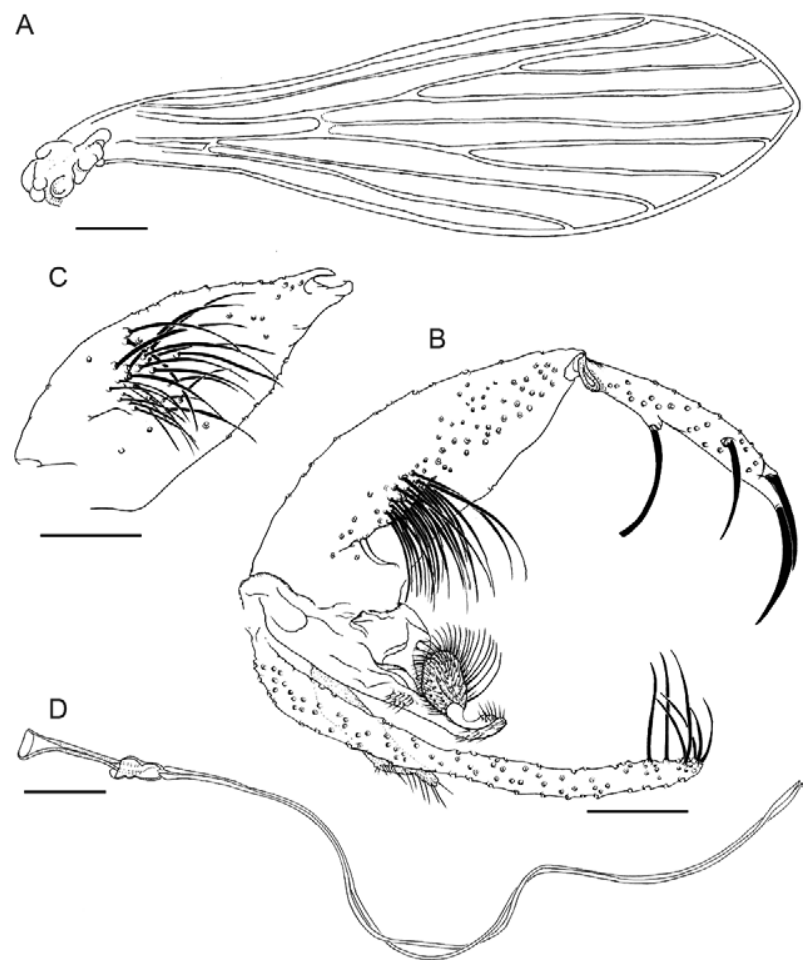

Fig. 3: Trichophoromyia adelsonsouzai sp. nov. (male holotype): A: wing; B: genitalia; C: other gonocoxite position; D: genital filaments. $\operatorname{Bar}=100 \mu \mathrm{m}$.
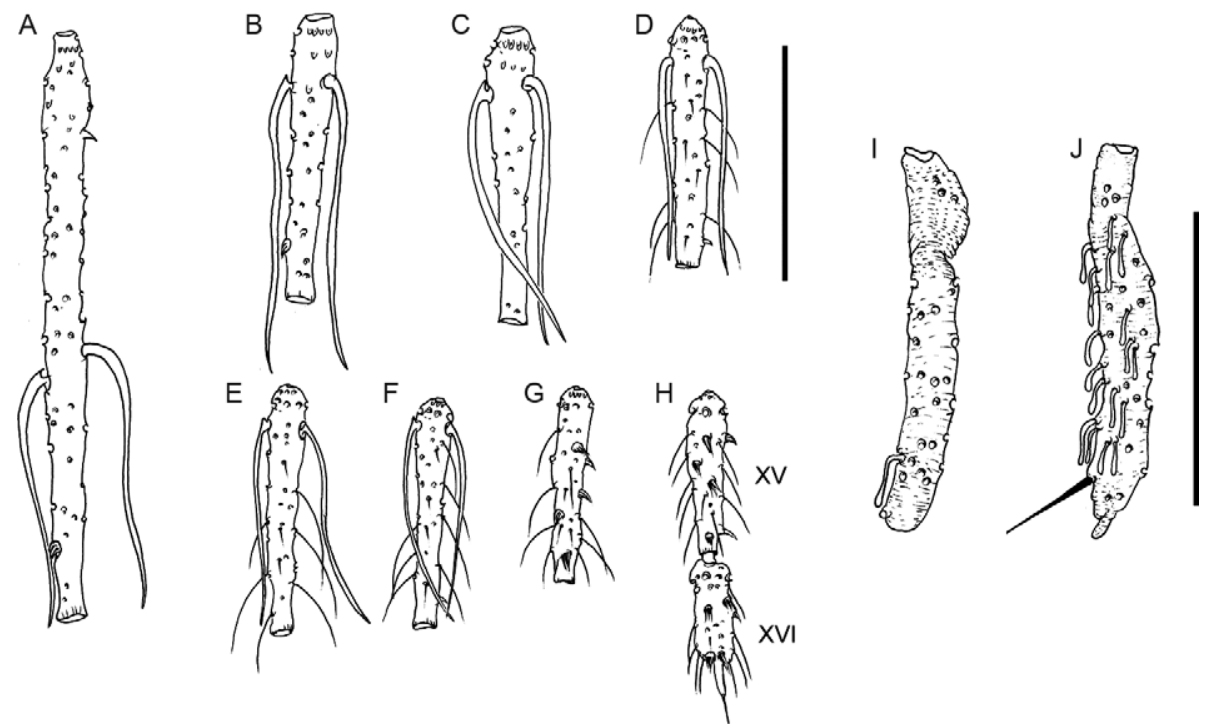

Fig. 2: antennomeres and palpomeres of Trichophoromyia adelsonsouzai sp. nov. (male holotype). A: AIII; B: AIV; C: AV; D: AXI; E: AXII; F: AXIII; G:AXIV, H: AXV and AXVI; I: palpomere I and II; J: palpomere III. Bar $=100 \mu \mathrm{m}$. 
Female - Head: (Fig. 1B) 410-450 $(\mathrm{n}=15)$ long, 301$370(\mathrm{n}=15)$ wide, ratio between length/width 1.2-1.4: 1.0 $(\mathrm{n}=15)$. Clypeus $120-170(\mathrm{n}=15)$ long; clypeus length/ head length ratio 0.3-0.4:1.0 $(\mathrm{n}=15)$. Eye 210-230 $(\mathrm{n}=$ $15)$ long; eye length/head length ratio $0.5-0.5: 1.0(n=15)$. Interocular distance 100-150 $(\mathrm{n}=15)$. LE 340-410 $(\mathrm{n}=$ 15); LE/head length ratio 0.8-0.9:1.0 $(\mathrm{n}=15)$. Antenna ( $\mathrm{n}$ $=15$ ): Antennomere III (Fig. 5A) with the external ascoid implanted slightly more basal than the internal one; ascoids without posterior spur, anterior prolongation long, reaching the distal end of the flagellomere; AIII and AIV with papilla implanted in the pre-apical region and absent in AV (Fig. 5A-C). Presence of simple setae on AVIII-AXVI $(n=9)$ and AXI, AXIII, AXV, AXVI with spiniform papilla $(\mathrm{n}=9)$ (Fig. 5D-G). Palpi: palpomere lengths: I 39-65 ( $\mathrm{n}=15)$; II 156-177 $(\mathrm{n}=15)$; III 185-208 ( $\mathrm{n}=15)$; IV 56-7 $(\mathrm{n}=15) ;$ V 156-182 $(\mathrm{n}=11)$. Palpal formula 1- 4- 25- $3(\mathrm{n}=11)$; palpomere II (Fig. 5H) with four Newstead's spines; palpomere III (Fig. 5I) with 13 Newstead's spines disperse on the middle of the structure. Cibarium (Fig. $6 \mathrm{~A})$ : 10-12 $(\mathrm{n}=11)$ horizontal teeth well developed and
16 vertical teeth. Pharynx not armed. Hypopharynx has 36 well-delimited short teeth situated in the apicolateral region. Lacinia of the maxilla with ca. 20 short internal teeth, arranged in a single row and ca. 15 external teeth arranged in two rows. Labial sutures form a fork.

Thorax: 600-750 $(\mathrm{n}=15)$ long; mesonotum 550$630(\mathrm{n}=15)$ long. Ventrocervical sensillae absent. 2-6 proepimeral setae; 9-16 anepisternal superior setae $(\mathrm{n}=$ 15). Setae absent on the anterior katepisternum margin. Wing (Fig. 6B): 1,250-2,500 $(\mathrm{n}=11)$ long, 620-700 $(\mathrm{n}=$ 10) wide; length/width 1.8-3.5:1.0 ratio; veins $R_{5} 1,330$ 1,490 ( $=8)$; alar indices: alpha 600-750 ( $\mathrm{n}=10)$; beta 230-310 ( $=10)$; gamma 220-290 ( $=9)$; delta 500-580 $(\mathrm{n}=9)$; pi 100-200 ( $\mathrm{n}=9)$. Length of coxa, femur, tibia, and tarsus $\mathrm{I}+\mathrm{II}+\mathrm{III}+\mathrm{IV}+\mathrm{V}$, respectively: foreleg $300-350$ $(\mathrm{n}=15), 750-870(\mathrm{n}=8), 980-1,120(\mathrm{n}=8), 1,270-1,520$ $(\mathrm{n}=8)$; midleg 300-340 ( $\mathrm{n}=15), 750-830(\mathrm{n}=5), 1,240$ $1,400(\mathrm{n}=5), 1,510-1,670(\mathrm{n}=5)$; hindleg 830-950 $(\mathrm{n}=$ 6), 890-910 (n=6), 1,450-1,620 (n=6), 1,630-2,000 (n= 6). Femora without spines.
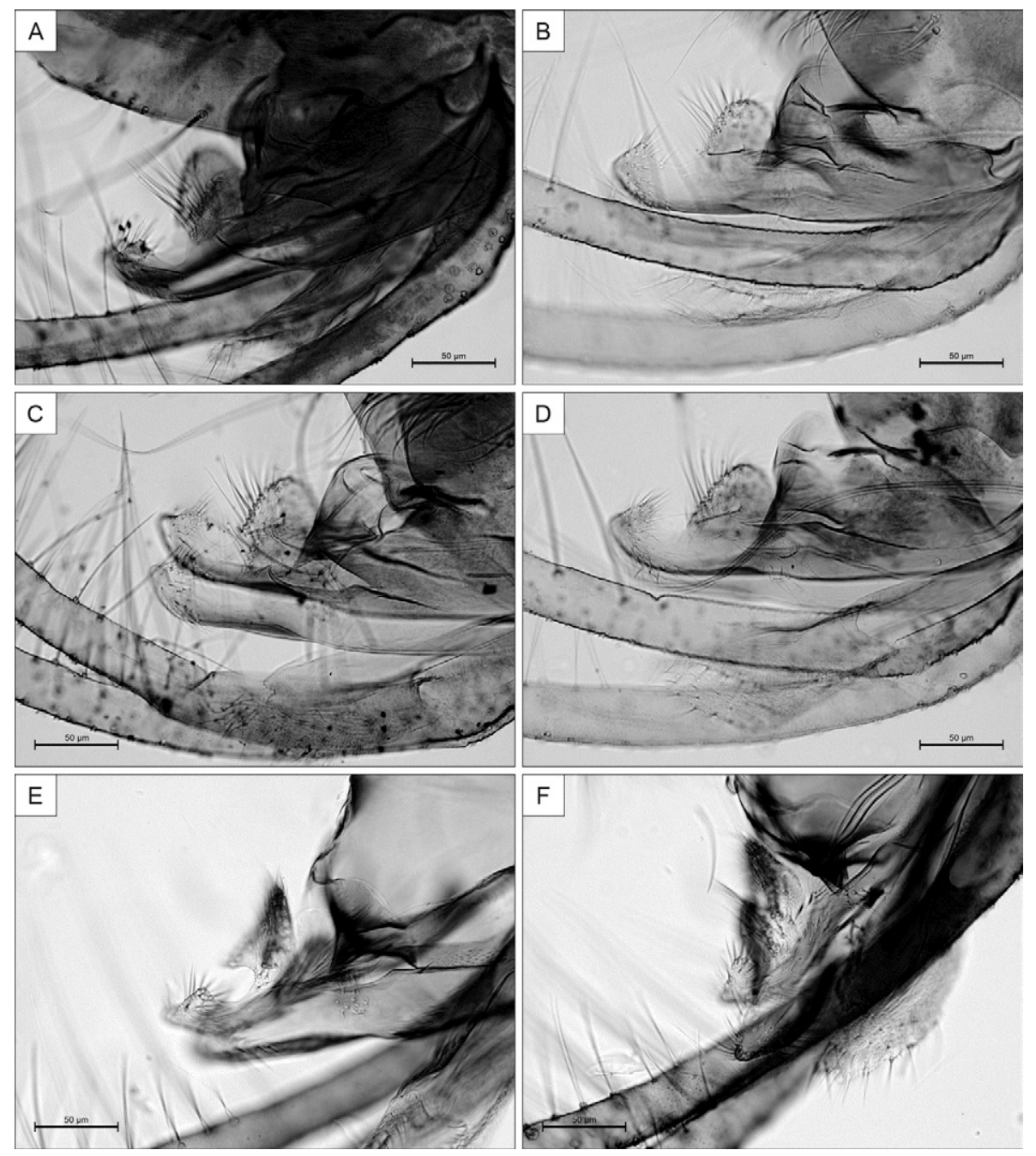

Fig. 4: parameres of Trichophoromyia adelsonsouzai sp. nov. A: male holotype; B-D: males paratypes (normal position); E, F: males paratypes showing the dorsal lobe bent downwards due to the pressure of the coverslip. 
Abdomen: 1,300-1,610 $(\mathrm{n}=15)$ long. Spermathecae (Fig. 6C) 75-148 $(\mathrm{n}=13)$ long; 13-16 $(\mathrm{n}=15)$ maximum width; spermathecae annulated ca. 42 rings as shown, individual ducts $13(\mathrm{n}=1)$ wide, membranous partially visible and common sperm duct no observed in all specimens; broad smooth head, ending in knob covered in "hairs". Apical ring until 30X $(\mathrm{n}=13)$ longer than the preapical. Cercus 91-117 $(\mathrm{n}=14)$ long, with oblong apex.

Type locality - Trans-Amazonian Highway, Km 27, between Altamira and Anapu.

Type data and depository - Male holotype, 31 male and 15 female paratypes collected with CDC light trap in Vitória do Xingu at 4-15 February and 10-26 July 2012. TVS and FMMS collectors. Type specimens are deposited in the Phlebotomines Collection of the Evandro Chagas Institute (IEC) (holotype, 13 male and 5 female paratypes) and the Entomological Collection Reference, School of Public Health, University of São Paulo (USP) (12 male and 4 female paratypes). Three paratype couples were deposited in the Phlebotomines Collection of the René Rachou Research Center, Oswaldo Cruz Foundation and three in the Museum of Zoology of the USP.

Distribution - Th. adelsonsouzai sp. nov. seems to be distributed along over Xingu basin once other nontype material were collected at Altamira, Senador José Porfírio and Anapu.

Bionomics - No data.

Etymology - We are pleased to name this species in honour to Mr Adelson Alcimar Almeida de Souza (in memoriam) that was researcher of IEC in recognition of his dedication to the study of sandflies and his contribution to knowledge of these insects in Brazilian Amazonia.

\section{DISCUSSION}

In view of the morphological similarity of the females of Trichophoromyia, many species are known only by the male and 19 species have been known by their females (Young \& Duncan 1994, Galati 2003). Among them, Trichophoromyia reburra (Fairchild \& Hertig, 1961) may be distinguished from the others by the presence of excrescences on the individual ducts of the spermathecae. Th. ubiquitalis, Trichophoromyia omagua (Martins, Llanos \& Silva, 1976) and Trichophoromyia cellulana (Young, 1979) present the apical ring of their spermatecae, less than three times longer than the previous one, while in Th. adelsonsouzai sp. nov. this ring is aproximately $30 \mathrm{X}$ longer, just as it is in the others 15 (Barreto et al. 2002, Galati 2003).

In the type-locality of Th. adelsonsouzai sp.nov., Vitória do Xingu, Trichophoromyia brachipyga (Mangabeira, 1942) was the only other species of the genus Trichophoromyia captured together. None specimens of Th. readyi has been collected yet in the sudied area, its type-locality is at Trans-Amazonica Highway, km 25 between Altamira and Itaituba, relatively close from the type-locality of $T h$. adelsonsouzai sp. nov. This fact led to think that the new species presents a intraespecific variation of Th. readyi (Ryan 1986). Morphological and morphometrical comparisons of the type-material of both species ruled out this possibility. We assumed the male and female specimens described above belong to the same species on mophological features such as coloration distribution on the thorax, but a study of its biology under laboratory condition will be needed to confirm this sex association.

The males of Th. adelsonsouzai sp. nov. are distincts of those Th. brachipyga which present gonocoxite with
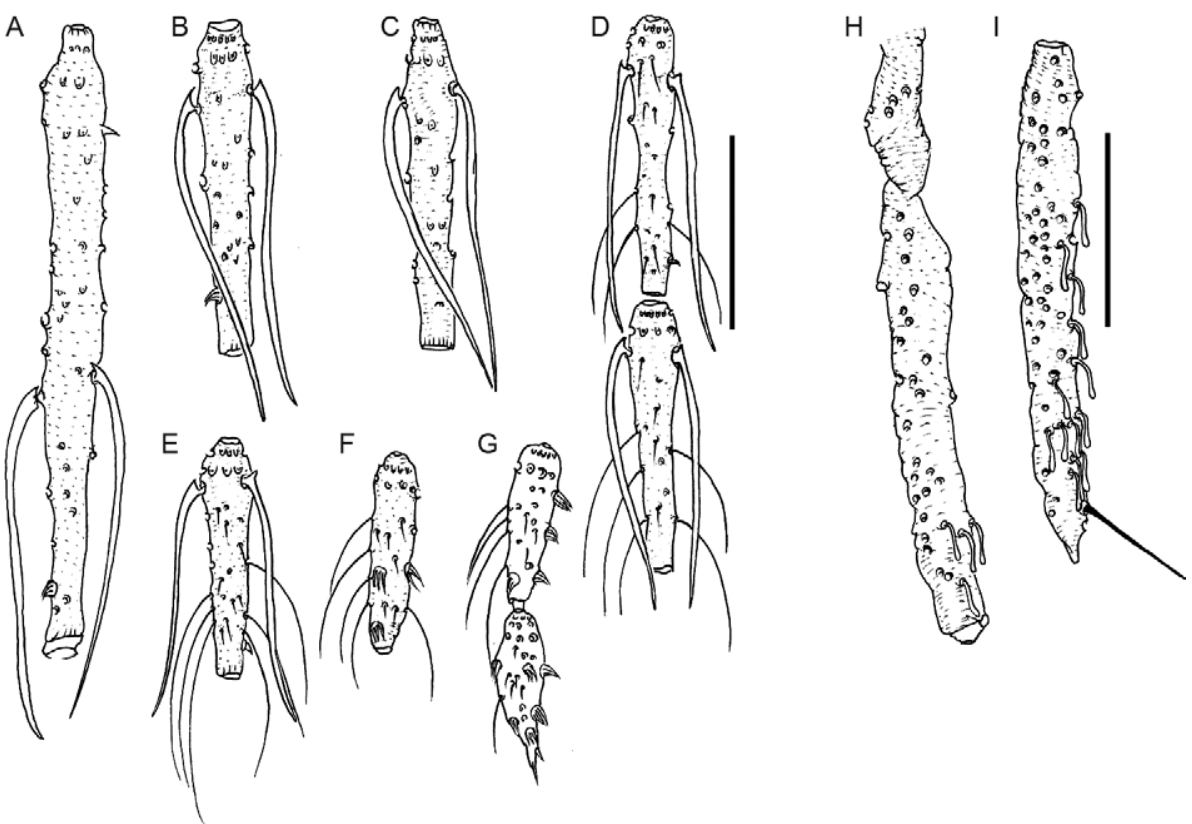

Fig. 5: antennomeres and palpomeres of Trichophoromyia adelsonsouzai sp. nov. (female paratype). A: AIII; B: AIV; C: AV; D: AXI and AXII; E: AXIII; F: AXIV; G: AXV and AXVI; H: palpomere I and II; I: palpomere III. Bar $=100 \mu \mathrm{m}$. 
four-seven spine-like setae included in group of numerous thinner setae (Mangabeira 1942), which are absent in this new species. Th. brachipyga present two long setae isolated from others, insided between proximal lobe and the apical region of paramere (Mangabeira 1942). These setae are absent in the new species and in Th. readyi, too closed species (Ryan 1986). However, in the gonocoxite of $T h$. readyi three-four very thick setae are present and absent in Th. adelsonsouzai sp. nov. In this new species, the length of the dorsal lobe of paramere is subequal to its height such as Th. readyi. The paramere of Th. adelsonsouzai sp. nov. presents a distinct curvature in the apical region that is absent in Th. readyi. This curvature is present in many other species such as Trichophoromyia viannamartinsi (Sherlock \& Guitton, 1970), Trichophoromyia gibba (Young \& Arias, 1994), Trichophoromyia dunhami (Causey \& Damasceno, 1945), Th. brachipyga, Trichophoromyia eurypyga (Martins, Falcão \& Silva, 1963), Trichophoromyia lopesi (Mangabeira, 1942) and Trichophoromyia inninii (Floch \& Abonnenc, 1943) (Damasceno et al. 1945, Martins et al. 1963). These last two species present setae at base of dorsal lobe that are absent in Th. adelsonsouzai sp. nov. In fact the paramere of the new species resembles that of Th. eurypyga, but the spines of the gonostylus is much more slender and long.

In relation to the morphological caracteres of others species of the genus Trichophoromyia recorded in Brazil, a group of long modified setae are present on the paramere of Trichophoromyia meirai (Causey \& Damasceno, 1945) and Th. ubiquitalis (Mangabeira 1942, Causey \& Damasceno 1945b) and they are absent in Th. adelsonsouzai sp. nov. The ausence of spine-like setae on the gonocoxite of Th. adelsonsouzai $\mathrm{sp}$. nov. distinguish it of Th. gibba, Th. dunhami and Th. viannamartinsi (Causey \& Damasceno 1945a, Sherlock \& Guitton 1970, Young \& Duncan 1994). The males of Trichophoromyia

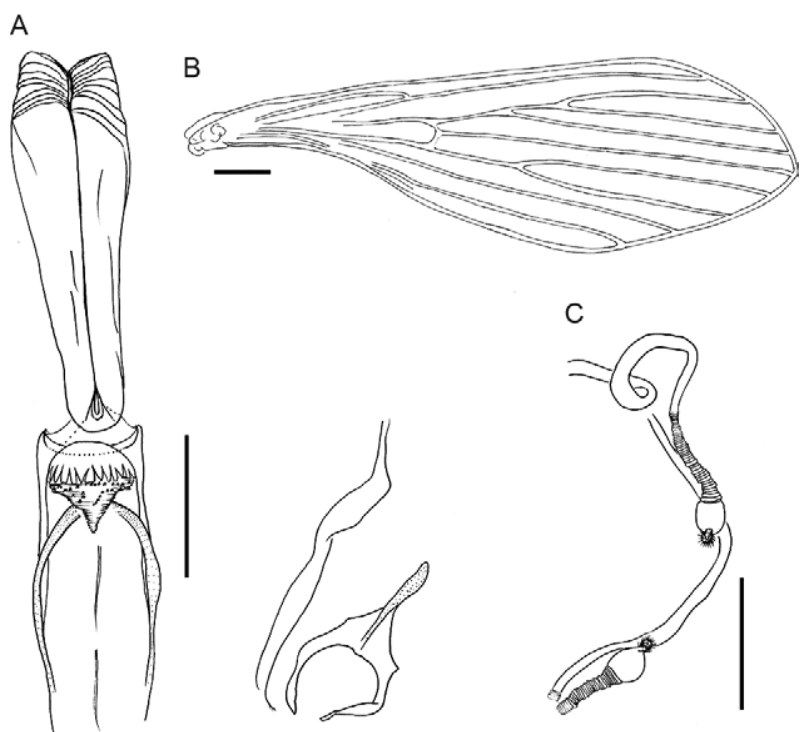

Fig. 6: Trichophoromyia adelsonsouzai sp. nov. (female paratype). A: pharynx and cibarium; B: wing; C: spermathecae. $\mathrm{Bar}=100 \mu \mathrm{m}$. ruii (Arias \& Young, 1982), Trichophoromyia rostrans (Summers, 1912), Trichophoromyia loretonensis (Llanos, 1964), Trichophoromyia octavioi (Vargas, 1949), Trichophoromyia flochi (Abonnenc \& Chassignet, 1948), Th. auraensis, Th. meirai and Th. ubiquitalis do not present dorsal lobe on the paramere (Young \& Duncan 1994, Galati 2003) while in Th. adelsonsouzai sp. nov. it is present (Fig. 4).

Gonocoxite with ca. 25 persistent setae in the middle of structure was observed in the new species, fewer (approximately 16) in Trichophoromyia castanheirai (Damasceno et al. 1945) and more than 30 in Th. loretonensis, Trichophoromyia howardi (Young, 1979), Th. ruii and Th. auraensis. Circular patch of ca. 15 modified long setae (recurved apically) is present near middle of the upturned paramere of Trichophoromyia reinerti (Young \& Duncan, 1994) and these set of setae is absent in all other Trichophromyia species, including Th. adelsonsouzai sp. nov. As like Th. readyi, the type-locality of $T h$. reinerti is realtively close from the new species, $164 \mathrm{Km} \mathrm{W}$ of Altamira (Young \& Duncan 1994), but yet none specimen of these two species has been captured in the type-locality of Th. adelsonsouzai sp. nov.

Th. adelsonsouzai sp. nov. distinguish from Trichophoromyia clitella (Young \& Pérez, 1994) due to the number of setae in the median tuft of gonocoxite, which in this latter species is 10 or less setae, and from Th. howardi because in this species the dorsal lobe of the paramere is shorter than that of Th. adelsonsouzai sp. nov. So far, Th. dunhami, Th. flochi, Th. gibba, Th. ininii, Th. lopesi, Th. loretonenis, Th. meirai, Th. rostrans and Th. viannamartinsi were not recorded in PA (Galati 2003), but can be reported in future studies. With the description of this new species the number of Trichophoromyia sandflies recorded in Brazil is increased to 20.

\section{ACKNOWLEDGEMENTS}

To the Norte Energia SA, for providing logistic facilities for field work, to Drs Marinete M Póvoa, Fernando T Silveira and José LB Ladislau, for logistic support and draw considerations in the manuscript, and to Luciene AS Santos, Roberto CF Brandão, Maria SB Pinheiro, José AN Lima, Edna F Leão and Ivanildo B Oliveira, for technician support.

\section{REFERENCES}

Aguiar GM, Medeiros WM 2003. Distribuição regional e habitats das espécies de flebotomíneos do Brasil. In EF Rangel, R Lainson, Flebotomineos do Brasil, Fiocruz, Rio de Janeiro, p. 207-256.

Artemiev MM 1991. A classification of the subfamily Phlebotominae. Parassitologia 33 (Suppl. 1): 69-77.

Barreto M, Burbano ME, Young DG 2002. Description of Lutzomyia (Trichophoromyia) pabloi $\mathrm{n}$. sp. and the female of $L$. howardi (Diptera: Psychodidae) from Colombia. J Med Entomol 39: 601-604.

Barretto MP 1962. Novos subgêneros de Lutzomyia França, 1924 (Psychodidae, subfamília Phlebotominae). Rev Inst Med Trop Sao Paulo 4: 91-100.

Causey OR, Damasceno RG 1945a. Estudo sôbre Flebotomus no vale Amazônico. Parte II. Descrição de F. dunhami, F. melloi e F. wagleyi (Diptera, Psychodidae). Mem Inst Oswaldo Cruz 42: 17-29.

Causey OR, Damasceno RG 1945b. Estudo sobre Flebotomus no Vale Amazônico. Parte IV - Descrição de F. cerqueirai, F. dreisbachi, 
F. meirai e F. ferreirai (Diptera - Psychodidae). Mem Inst Oswaldo Cruz 42: 645-660.

Damasceno RG, Causey OR, Arouck R 1945. Estudos sobre Flebotomus no Vale Amazônico. Parte V - Descrição de F. williamsi, $F$. deanei, F. carvalhoi, F. lopesi, F. castanheirai, $F$. fariasi, $F$. baityi e F. campbelli (Diptera - Psychodidae). Mem Inst Oswaldo Cruz 43: 1-30.

Fairchild GB, Hertig M 1961. Notes on the Phlebotomus of Panama. XVI. (Diptera, Psychodidae). Descriptions of new and littleknown species from Panama and Central America. Ann Entomol Soc Am 54: 237-255

Floch H, Abonnenc E 1943. Phlébotomes de la Guyane Française. V. Pub Inst Pasteur Guyane Française 61: 1-30.

Forattini OP 1973. Entomologia médica. Psychodidae. Phlebotominae. Leishmanioses. Bartonelose, Vol. IV, Edgard Blücher, São Paulo, 658 pp.

Galati EAB 1995. Phylogenetic systematics of Phlebotominae (Diptera, Psychodidae) with emphasis on American groups. Bol Dir Malariol San Amb 35: 133-142.

Galati EAB 2003. Morfologia, terminologia de adultos e identificação dos táxons da América. In EF Rangel, R Lainson, Flebotomíneos do Brasil, Fiocruz, Rio de Janeiro, p. 53-175.

Lainson R, Shaw JJ 1998. New world leishmaniasis. The Neotropical Leishmania species. In FEG Cox, JP Kreier, D Wakelin, Topley \& Wilson's microbiology \& microbiol infections, Parasitology Arnold, London, p. 242-266.

Lainson R, Shaw JJ, Souza AAA, Silveira FT, Falqueto A 1992. Further observations on Lutzomyia ubiquitalis (Psychodidae: Phle- botominae), the sandfly vector of Leishmania (Viannia) lainsoni. Mem Inst Oswaldo Cruz 87: 437-439.

Mangabeira Filho O 1942. $7^{\text {a }}$ Contribuição ao estudo dos Flebotomus (Diptera: Psychodidae). Descrição dos machos de 24 novas espécies. Mem Inst Oswaldo Cruz 37: 111-218.

Marcondes CB 2007. A proposal of generic and subgeneric abbreviations for phlebotomine sandflies (Diptera: Psychodidae, Phlebotominae). Entomol News 118: 351-356.

Martins AV, Falcão AL, Silva JE 1963. Notas sobre os flebótomos do território de Roraima, com a descrição de três novas espécies (Diptera, Psychodidae). Rev Bras Biol 23: 333-348.

Martinez E, Le Ponte F, Mollinedo S, Cupollilo EA 2001. First case of cutaneous leishmaniasis due to Leishmania (Viannia) lainsoni in Bolivia. Trans R Soc Trop Med Hyg 95: 375-377.

Ryan L 1986. Flebótomos do estado do Pará, Brasil (Diptera: Psychodidae), Instituto Evandro Chagas/Fundação SESP/Ministério da Saúde, Belém, 154 pp.

Sherlock IA, Guitton N 1970. Notas sobre o subgênero Trichophoromyia Barretto, 1961 (Diptera, Psychodidae, Phlebotominae). Rev Bras Biol 30: 137-150.

Valdivia HO, de los Santos MB, Fernandez R, Baldeviano GC, Zorrilla VO, Vera H, Lucas CM, Edgel KA, Lescano AG, Mundal KD, Graf PC 2012. Natural Leishmania infection of Lutzomyia (Trichophoromyia) auraensis in Madre de Dios, Peru, detected by a fluorescence resonance energy transfer-based real-time polymerase chain reaction. Am J Trop Med Hyg 87: 511-517.

Young DG, Duncan MA 1994. Guide to the identification and geographic distribution of Lutzomyia sandflies in Mexico, the West Indies, Central and South America (Diptera: Psychodidae), Associated Publishers, Gainesville, $881 \mathrm{pp}$. 